GT2017-64051

\title{
MICROSTRUCTURE BASED MATERIAL-SAND PARTICULATE INTERACTIONS AND ASSESSMENT OF COATINGS FOR HIGH TEMPERATURE TURBINE BLADES
}

\author{
Dr. Muthuvel Murugan, Dr. Anindya Ghoshal, Dr. Michael Walock, Dr. Andy Nieto, Dr. Luis Bravo, \\ Mr. Blake Barnett, Mr. Marc Pepi, and Dr. Jeffrey Swab \\ U.S. Army Research Laboratory, Aberdeen Proving Ground, MD, USA \\ Mr. Robert Tyler Pegg, \\ Mr. Chris Rowe \\ NAVAIR \\ Dr. Dongming Zhu \\ NASA Glenn Research Center \\ Cleveland, OH, USA \\ Mr. Kevin Kerner \\ AMRDEC - ADD \\ Fort Eustis, VA, USA
}

Patuxent River, MD, USA

\section{ABSTRACT}

Gas turbine engines for military/commercial fixedwing and rotary wing aircraft use thermal barrier coatings in the high-temperature sections of the engine for improved efficiency and power. The desire to further make improvements in gas turbine engine efficiency and high power-density is driving the research and development of thermal barrier coatings with the goal of improving their tolerance to fine foreign particulates that may be contained in the intake air. Both commercial and military aircraft engines often are required to operate over sandy regions such as in the middle-east nations, as well as over volcanic zones. For rotorcraft gas turbine engines, the sand ingestion is adverse during take-off, hovering near ground, and landing conditions. Although most of the rotorcraft gas turbine engines are fitted with inlet particle separators, they are not $100 \%$ efficient in filtering fine sand particles of size 75 microns or below. The presence of these fine solid particles in the working fluid medium has an adverse effect on the durability of turbine blade thermal barrier coatings and overall performance of the engine. Typical turbine blade damage includes blade coating wear, sand glazing, CalciaMagnesia-Alumina-Silicate (CMAS) attack, oxidation, and plugged cooling holes, all of which can cause rapid performance deterioration including loss of aircraft. The objective of this research is to understand the fine particle interactions with typical turbine blade ceramic coatings at the microstructure level. Finite-element based microstructure modeling and analysis has been performed to investigate particle-surface interactions, and restitution characteristics. Experimentally, a set of tailored thermal barrier coatings and surface treatments were downselected through hot burner rig tests and then applied to first stage nozzle vanes of the gas generator turbine of a typical rotorcraft gas turbine engine. Laser Doppler velocity measurements were performed during hot burner rig testing to determine sand particle incoming velocities and their rebound characteristics upon impact on coated material targets. Further, engine sand ingestion tests were carried out to test the CMAS tolerance of the coated nozzle vanes. The findings from this on-going collaborative research to develop the next-gen sand tolerant coatings for turbine blades are presented in this paper.

\section{INTRODUCTION}

Over the years, through consistent efforts in advanced materials development, scientists and engineers have significantly improved the efficiency and power densities of gas turbine engines by increasing the turbine inlet temperature using high-temperature capable blade materials and coatings. Traditionally, foreign object damage (FOD) has been the primary concern in aviation and tank automotive gas turbine engines. Current state-of-the-art inlet particle separators equipped in gas turbine engines can remove most of the larger sized particles (greater than $\sim 75 \mu \mathrm{m}$ ) from the inlet air. This, in 
combination with high-quality, erosion-resistant coatings on the compressor sections, has significantly reduced the risk from FOD in the cold sections of the engine. However, fine micronsized particles (consisting of ash, soot, dust, and/or sand) can still pass through the engine and create problems in the hotsections, where the operating temperatures of modern gas turbine engines typically surpass the melting point of many of these contaminants. The resulting impact, adhesion, melt infiltration and/or glassy solidification of these small particles can significantly damage the hot-section components within the gas turbine engine [1].

High pressure gas generator turbine blades typically experience inlet temperatures of $1300-1600^{\circ} \mathrm{C}$, requiring $\mathrm{TBCs}$ to be used as thermal insulators on the turbine blades to reduce blade cooling needs. Current state-of-the-art gas turbine blade technology has four layers in the high temperature turbine blade coating system that consists of different materials with specific properties and functions. These layers are (i) the Ni-based superalloy substrate, (ii) bond coat, (iii) thermally grown oxide (TGO) (Alumina, $\mathrm{Al}_{2} \mathrm{O}_{3}$ ), and (iv) the ceramic top-coat (YSZ, Yttria stabilized Zirconia) [2, 3]. These four layers and their nominal coating thickness ranges are shown in Figure 1. These discrete multilayer materials have shown vulnerability to intake flows that contain sand, dust, and/or fly ash, which adhere and react at high temperatures and cause premature component failure through both impingement and combined mechanicalthermal-chemical attack. Currently there are no valid fundamental physics based models [1-3] to describe the complex phenomena of molten particulate impingement, adhesion and melt infiltration into the ceramic TBCs, followed by subsequent phase change to glassification [4,5] and underlying chemical oxidation leading to failure/delamination of the coating layers. A collaborative research effort at the U.S. Army Research Laboratory (ARL), with the U.S. Army Aviation and Missile Research, Development, and Engineering Center (AMRDEC), the U.S. Navy Naval Air Systems Command (NAVAIR) and the National Aeronautics and Space Admininstration (NASA), has been initiated to conduct research to understand the complex fine sand particulate interaction mechanisms with thermal barrier coatings and bulk material substrates [6-12].

Field-returned engine hardware from Army rotorcraft from Southwest Asia (SWA) shows a significant number of occurrences of sand-induced damage (Figure 2) [13]. Army rotorcraft engines are being pulled out of service at a substantial knockdown on the design life. Commercial jet engines flying over dust polluted urban areas in some parts of Far East Asia and South Asia also find sub-micron particles in a molten/semimolten state after passing through the combustor. Novel TBCs which are also resistant to sand-induced surface degradation can greatly reduce vulnerability in hostile particle-laden environments and increase fuel efficiency of gas turbine engines for both the military rotorcraft and civil aircraft fleet. Figures 3(a) and 3(b) show sand-induced CMAS (Calcium-MagnesiumAluminum-Silicates) formation on field returned engine hardware (turbine shroud) and from an engine sand ingestion test using AFRL03 sand showing good correlation of CMAS presence. This paper outlines the continued research efforts at ARL to develop novel TBCs that are sand-phobic with excellent resistance to impact wear and CMAS adherence, together with excellent thermal strain tolerance and very low thermal conductivity properties for improved performance of future gas turbine engines.

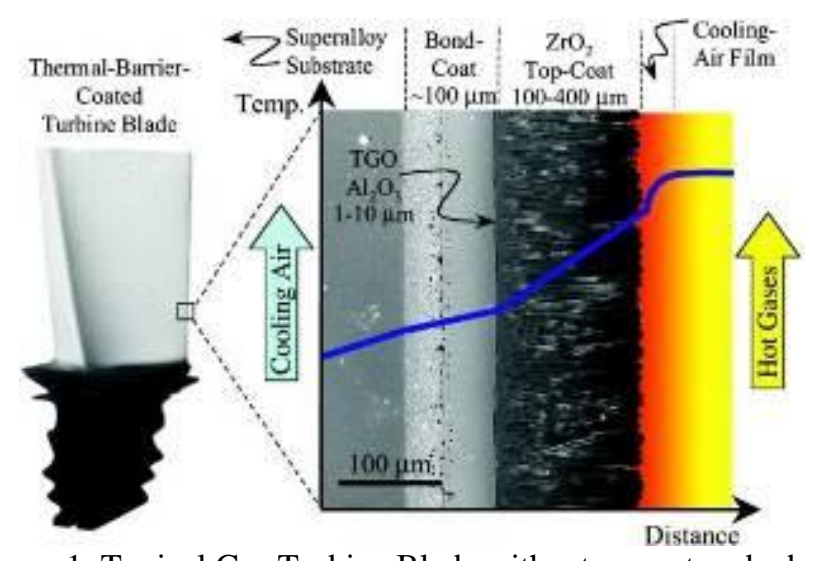

Figure 1. Typical Gas Turbine Blade with a top-coat and a bond coat with thermally grown Al-oxide layer [3] (Reprinted with permission from AAAS).

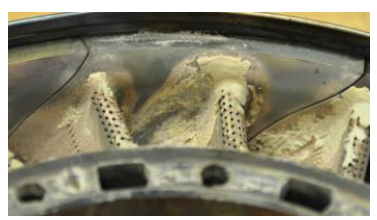

Typical build-up on vane

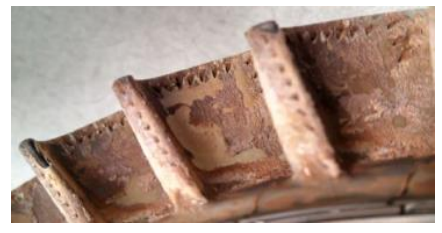

Typical build-up on blade
Figure 2: Engine turbine nozzle and rotor blades with typical sand-induced damage.
Field-returned Shroud

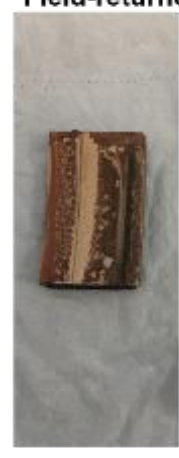

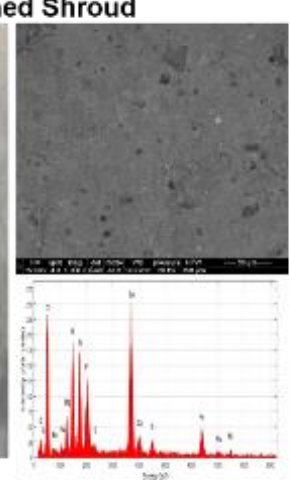

Engine-test Shroud
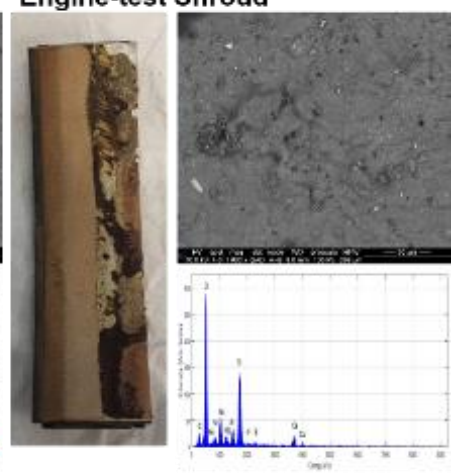

Figure 3(a). Field-returned and Engine Test Hardware (GTE shroud) showing CMAS formation. 


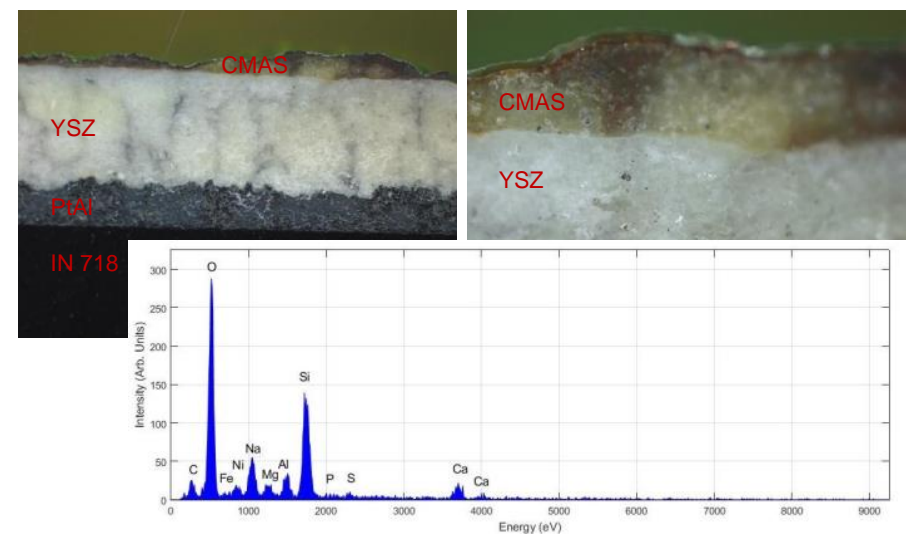

Figure 3(b). Detailed Microscopic image and elemental analysis of CMAS formed on the Engine Test Shroud.

\section{NOMENCLATURE}

APS Air Plasma Spray

AFRL Air Force Research Laboratory

ARL Army Research Laboratory

AMRDEC Army Aviation and Missile Research, Development, and Engineering Center

CMAS Calcia-Magnesia-Alumina-Silicate

CMC Ceramic Matrix Composite

CFD Computational Fluid Dynamics

CTE Coefficient of Thermal Expansion

EB-PVD Electron Beam Physical Vapor Deposition

EBC Environmental Barrier Coating

FOD Foreign Object Damage

HVAF High Velocity Air-Fuel

HVOF High Velocity Oxy-Fuel

$\mathrm{m} / \mathrm{s} \quad$ meters per second

$\mu \mathrm{m} \quad$ micrometer

ms milliseconds

NAVAIR Naval Air Systems Command

NASA National Aeronautics and Space Administration

SEM Scanning Electron Microscope

$\mathrm{SiC} \quad$ Silicon Carbide

SPPS Solution Precursor Plasma Spray

SWA Southwest Asia

SPD Supersonic Particle Deposition

TBC Thermal Barrier Coating

TGO Thermally Grown Oxide

YSZ Yttria Stabilized Zirconia

\section{PARTICLE INTERACTIONS RESEARCH STUDY}

Technical challenges involve modeling complex thermomechanical interactions of mechanics of particle impact and adherence. The particles can be fully or partially molten or remain in their solid state after flowing through the combustor depending upon their size, morphology, geological location and composition (sand melting point varies between $\sim 1050-1250$ $\left.{ }^{\circ} \mathrm{C}\right)$. Since the particle impact on turbine blades is much more complex with multi-physics phenomena including thermo- mechanical interactions and chemical reactions, a step-by-step canonical approach is being taken at the U.S. Army Research Laboratory to study the blade surface-particle interaction. Figure 4 describes the damage mechanisms as intrinsic and extrinsic in nature [14]. Intrinsic damage evolutions are caused by thermo-mechanical fatigue characteristics of the coating and substrate materials and their interface bonding strengths. Extrinsic damage evolutions are influenced by particle impact causing wear and erosion of TBC. Further, the molten sand deposition, infiltration into the micro-gaps of $\mathrm{TBC}$ and the solidification causes the TBC to lose its thermal strain tolerance leading to typical horizontal cracks and subsequent delamination of TBC.
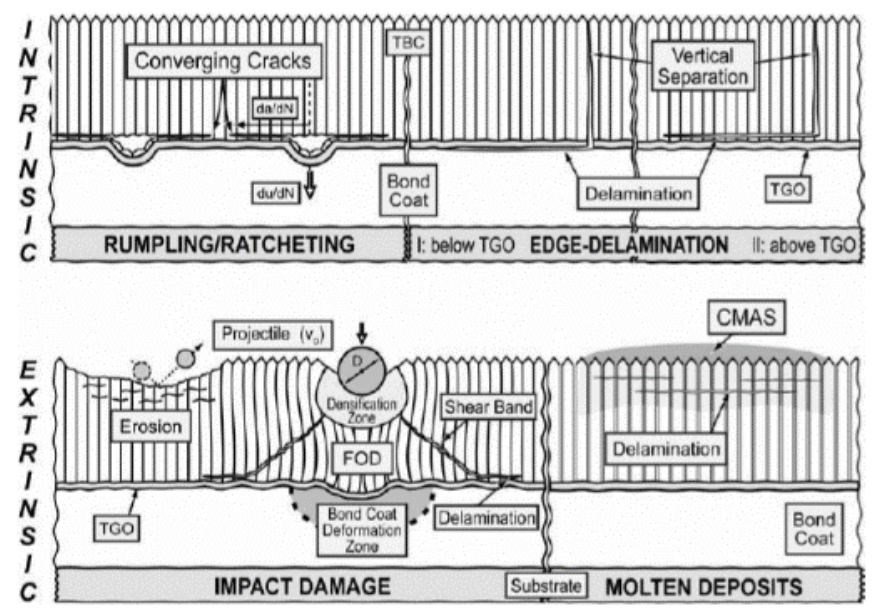

Figure 4. Typical damage mechanisms due to particulate interactions with TBC layer [14]

As a first step, a spherical particle (quartz sand composition) impacting a flat target made of typical turbomachinery material was developed using a nonlinear dynamic impact analysis finite-element code, LS-DYNA [15]. Researchers in the past have developed semi-empirical erosion models by studying the rebound characteristics of sand particles impacting turbomachinery materials [17-20]. Figure 5 is a SEM image of a typical gas turbine blade showing the columnar structure of the 7YSZ TBC layer. In this research effort, a micro-structure finite-element model similar to the microstructure of TBC on a substrate has been developed, as shown in Figure 6, to study the particle impact physics including particle kinematics, propensity of particulate adhesion to the surface and buildup in addition to local damage on target material surfaces. The meso-scale finite-element model is being extended to further develop simulation of liquid sand particle (molten sand) impacting a thermal barrier coated turbine blade surface as the next step. Further, the model shown in Figure 6 was modified to simulate multiple sharp-edged fine sand particles. Figure 7 shows the typical substrate/TBC model with multiple irregular, sharp-edged sand particles of $50 \mu \mathrm{m}$ in mean size (equivalent geometry envelope diameter). 


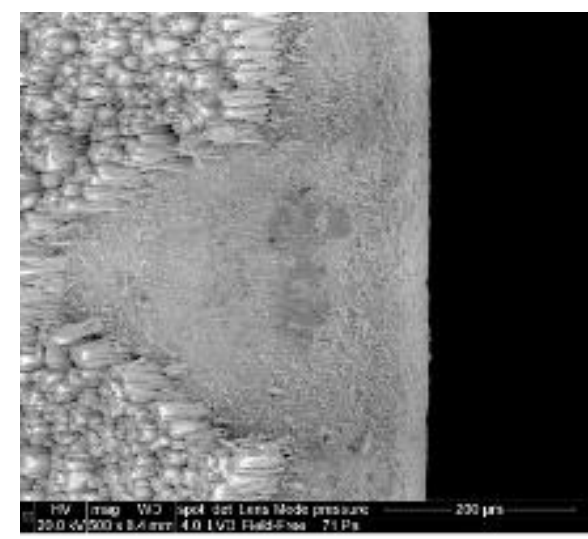

Figure 5. SEM image of a typical gas turbine blade showing the columnar structure of the 7YSZ

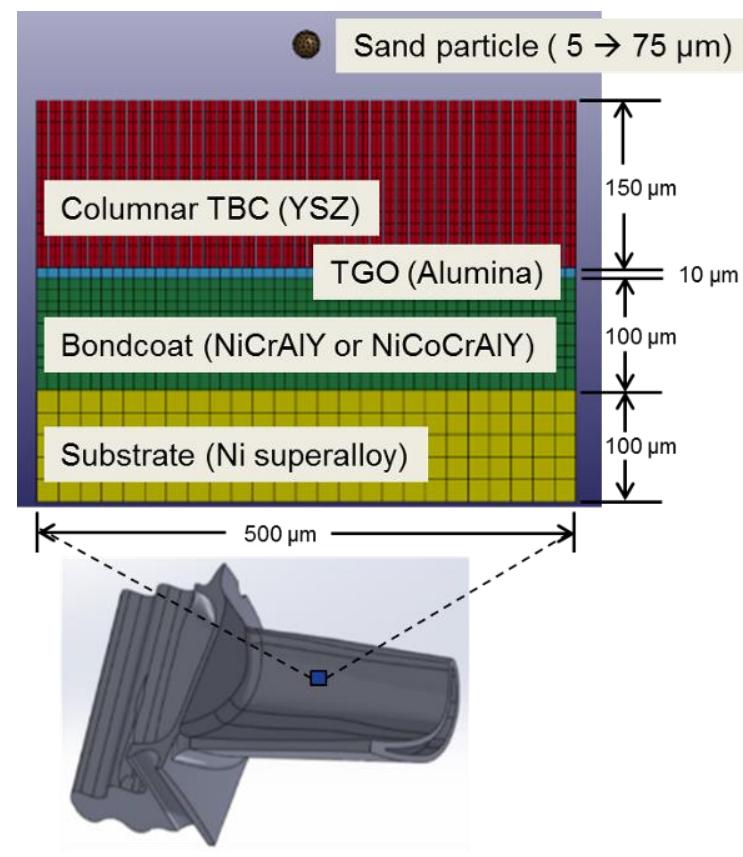

Typical high-pressure turbine blade

Figure 6. Meso-scale Blade Surface - Particle Dynamic Impact Model

\section{Sand Particle Impact Simulation}

Non-linear dynamic impact analysis software, LSDYNA was used to simulate multiple sand particle impacts on a micro-structure model consisting of typical interface layers as shown in Figures 6 and 7. In this simulation, the irregular, sharp-edged sand particles were assigned silica quartz material properties, and were assumed rigid through the use of Mat_Rigid material model available in LSDYNA. Material data were obtained from published references and used for the four layers of blade materials, shown in Figure 6. Elastic-plastic material model, called Mat_Plastic available in LS-DYNA solver was used for all four layers. Surface_to_Surface contact algorithm available in the software was utilized for each particle-surface interaction contacts with columnar TBC that has intercolumnar gaps of $2 \mu \mathrm{m}$. Tied_Contact algorithm (available in LS-DYNA) was used for the interfaces between layers. The particle velocities and plastic strain build up on the TBC were tracked through the simulation runs. For each particle, initial velocity of $200 \mathrm{~m} / \mathrm{s}$ (Mach number $\sim 0.6$ at ambient temperature) with an impact angle of 45 degrees was used to run the impact simulation. This simulation method will be further developed to analyze molten sand particle impact interactions with target material properties at gas turbine relevant temperatures and a range of particle velocities and impact angles.

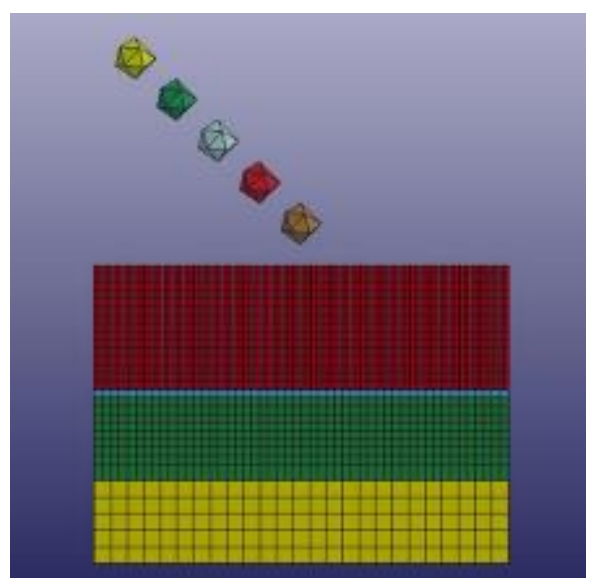

Figure 7. TBC surface - multiple particle (irregular sharp-edged) impact model

The numerical solution provides stresses, strains, deformations, etc., including velocity history during particle-surface impact interactions. The explicit computations were terminated after the particles reached almost steady rebound velocities. The plastic strains on the columnar TBC surface are shown in Figure 8. The particle velocity time histories are shown in Figure 9. These results show that a there is significant plastic strain build up accumulation on the TBC surface during multiple particle impact. The plastic strain build up is due to the transfer of kinetic energy from multiple particles being imparted to the TBC surface. Due to multiple particle impact, considerable amount of particle kinetic energy is absorbed by the TBC since the rebound velocity for each particle is reduced to about $25 \%$ of initial velocity. Although the comparison with spherical particles [13] is not shown in this paper, we have also observed that the impact energy absorption resulting from the irregular shaped particulates is higher leading to a deeper plasticity zone as shown in Figure 8. 


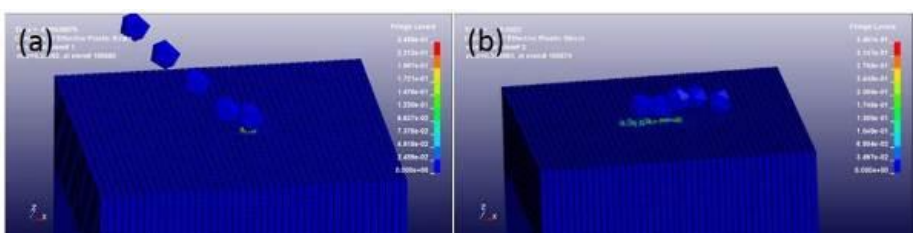

Figure 8. Plastic strain on TBC during impact from (a) the first particle and (b) subsequent particles.

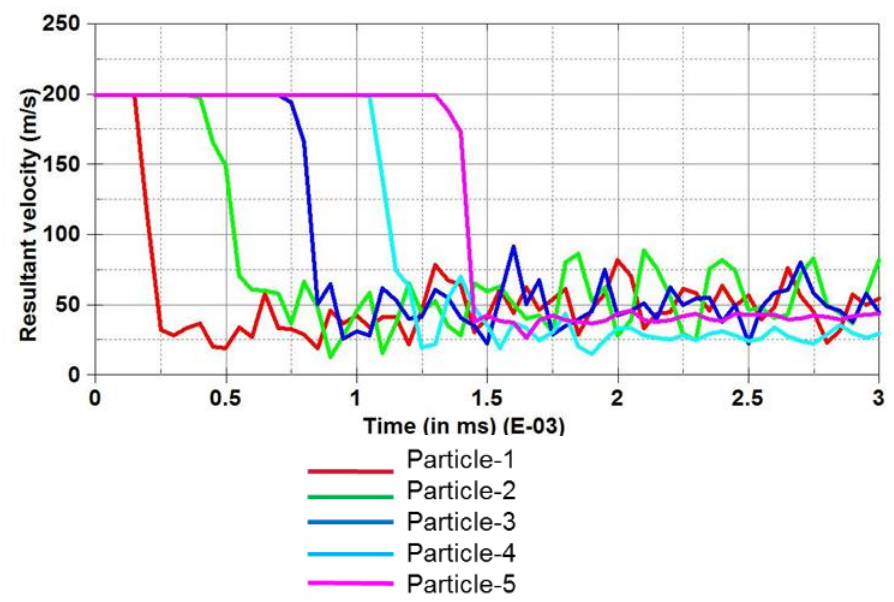

Figure 9. Particle velocity change during surface interactions (from multiple particle impact simulation)

\section{Sand Particle Melting Simulation}

In order to verify whether a fine sand particle can melt during its flight through the combustor, a multi-physics finite-element simulation using Multiphysics v5.0 (COMSOL, Inc.) was carried out [13]. Multiphysics is a finite-element based simulation program that solves the coupled partial differential equations (of different physiochemical phenomena) simultaneously. The first order model helps us to understand the amount of thermal exposure within the combustor leading to a molten or semimolten condition of the sand particulate. The COMSOL simulation is a 2D axisymmetric model, with the diameter of the spherical particle varying between $100 \mathrm{~nm}-500 \mu \mathrm{m}$. The initial particle core temperature is assumed to be 425 ${ }^{\circ} \mathrm{C}$ (typical air flow temperature at the exit of final stage of compressor in a rotorcraft gas turbine engine) and the outer wall temperature of the particle is ramped to $1400{ }^{\circ} \mathrm{C}$. Figure 10(a) shows a typical spherical sand particulate. Figure 10(b) illustrates the temporal requirement for the melting of sand particulate of different diameters. Particles smaller than $100 \mu \mathrm{m}$ will fully melt within $10 \mathrm{~ms}$ of exposure. For a particle in the turbulent flow within the combustor, this is sufficient exposure time to fully melt.

The test sand properties are given in Figure 10(c); these values are based on published data for the test sand, AFRL 02 [16]. AFRL 02 test sand is a commerciallyavailable mineral-based synthetic sand (34 wt.\% quartz, 30 wt.\% gypsum, 17 wt.\% aplite, 14 wt.\% dolomite, and 5 wt.\% salt). This material was developed to mimic the effects seen on fielded engine hardware in a laboratory test environment. The resulting synthetic sand has a nonspherical morphology, with a wide particle distribution $(0.5$ - $150 \mu \mathrm{m}$; mean particle diameter $15 \mu \mathrm{m}$ ), and the melting temperature $\left(1140^{\circ} \mathrm{C}\right)$ falls well within the range of natural sands $\left(1050-1250^{\circ} \mathrm{C}\right)$.
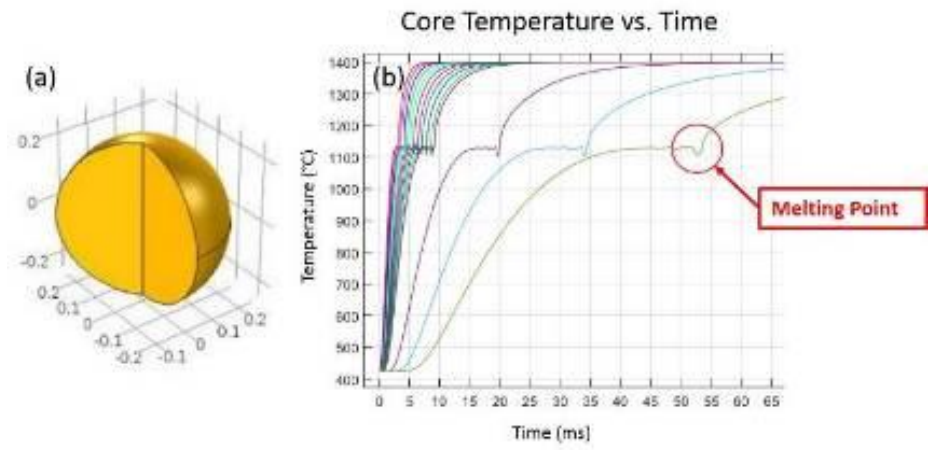

\begin{tabular}{|l|l|}
\hline Test Sand Property & Value \\
\hline Melting Temperature & $1140^{\circ} \mathrm{C}$ \\
\hline Latent Heat of Fusion & $145 \mathrm{~kJ} / \mathrm{kg}$ \\
\hline Density (solid) & $2.27 \mathrm{~g} / \mathrm{cc}$ \\
\hline Thermal conductivity (solid) & $1.4 \mathrm{~W} /\left(\mathrm{m}^{*} \mathrm{~K}\right)$ \\
\hline CTE & $5.6 \times 10^{-7} /{ }^{\circ} \mathrm{C}$ \\
\hline
\end{tabular}

Figure 10(a). A typical spherical sand particulate. Figure 10(b). Temporal requirement for melting of sand particulate of different diameters exposed to combustor temperature. Figure 10(c). Test sand properties used for the thermal calculation.

High-speed imagery of sand impacting on the surface of a TBC-coated Inconel 718 one inch disk confirms the molten nature of the sand contaminants in the combusted gas airflow. The image sequence (Figure 11) shows the flight path of a sand particle, its impact splat on the sample surface, and subsequent plume of material resulting from the impact. This confirms the first-order melting model results shown in Figure 10(b).
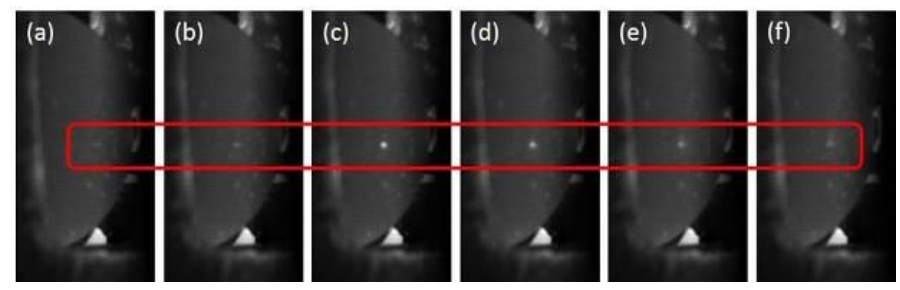

Figure 11. High-speed images (using a Photron SA-5 at 140 kfps) of a molten sand particle's impact on the surface of a TBC. (Note the presence of a material plume, from the impact, in the last two frames (e and f)). 
In addition, particle velocity measurements were carried out using a Dantec two-component laser Doppler velocimetry system during thermal cycling testing of coated samples with sand ingestion using the hot particulate burner rig facility at ARL (shown in Figure 14(b)). Molten sand particle velocity measurements were obtained at the exit of the jet burner in the center of the flame, and at a point close to the surface of a coated Inconel circular disk sample in the flame. Figure 12(a) shows the free stream impacting velocities of molten sand particles, and Figure 12 (b) shows the rebound velocities of the molten liquid sand particles close to the sample surface. From these data, it is evident that most of the impacting molten sand particles lose their kinetic energy resulting in deposition onto the TBC surface.
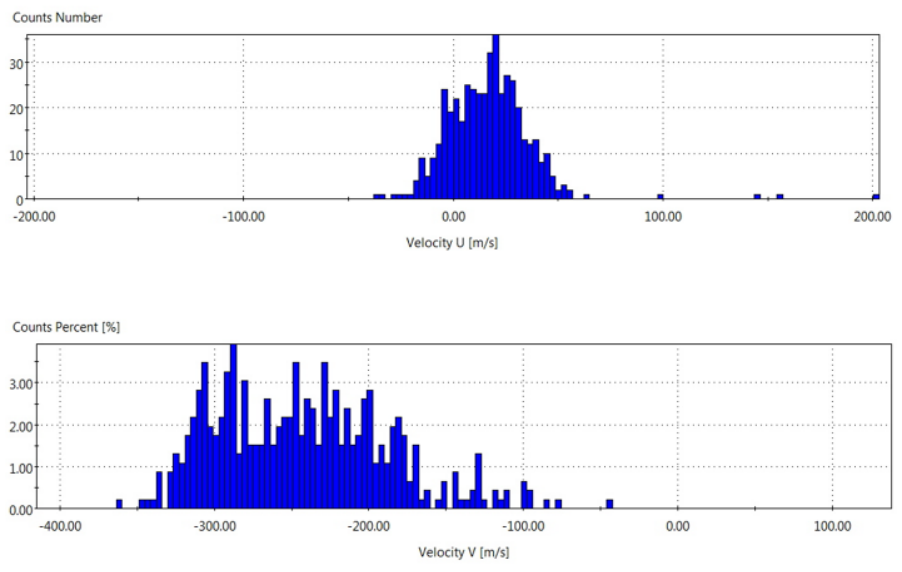

Fig. 12(a). Two-component (U, V) free stream velocities of molten sand particles (at burner exit)
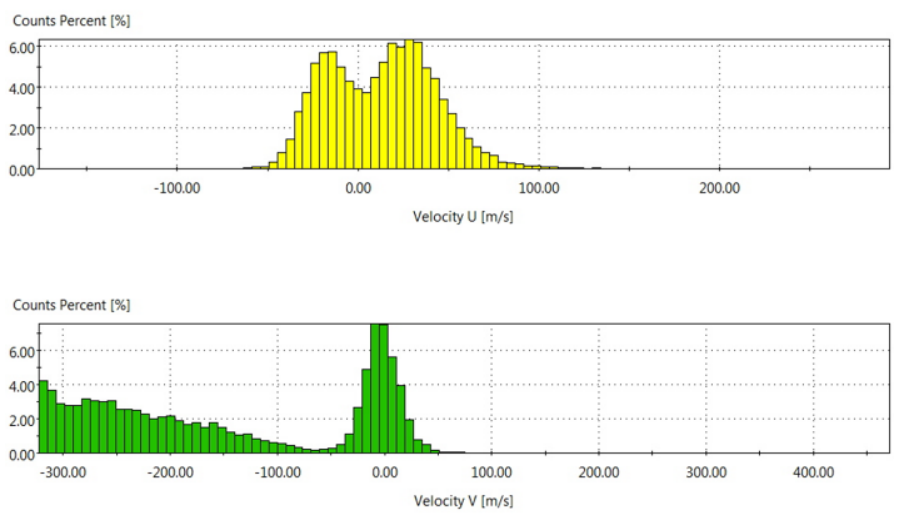

Fig. 12(b). Two component (U, V) rebound velocities of molten sand particles (close to sample surface)

\section{Sand Particle Trajectory Simulations}

In order to determine the vulnerable impact zones inside a typical turbine nozzle passage, computational fluid dynamics simulations were performed and then particle trajectory simulations were carried out. From these simulations, vulnerable zones of the blades where sand accumulation could occur, were identified. The particle trajectory and wall interactions were simulated using a fixed stator/rotor cascade geometry as shown in Figure 13. The flow inlet conditions studied were as follows, inflow velocity of $82.3 \mathrm{~m} / \mathrm{s}$, temperature of $1400{ }^{\circ} \mathrm{C}$, with pressure at $294 \mathrm{psi}$, and the geometry was positioned sufficiently downstream and away from boundaries as to avoid outflow numerical disturbances. The concept model is based on earlier works using EulerianLagrangian particle injection methodology and it is coupled with the surrounding carrier gas-phase turbulent environments [21]. The flow turbulence is modeled via a Reynolds Average Navier Stokes (RANS) approach and adaptive mesh refinement (AMR) that resolves the flow field in local intensity regions accurately and efficiently. At the blade surface, a law of the wall model is utilized at a location of $y+=50$ to avoid the excessive cost of resolving the viscous region. The surrogate model assumes the sand particle is in the molten state, as it leaves the combustion chamber, and prescribes molten silicon dioxide $\left(\mathrm{SiO}_{2}\right)$ physical transport properties.
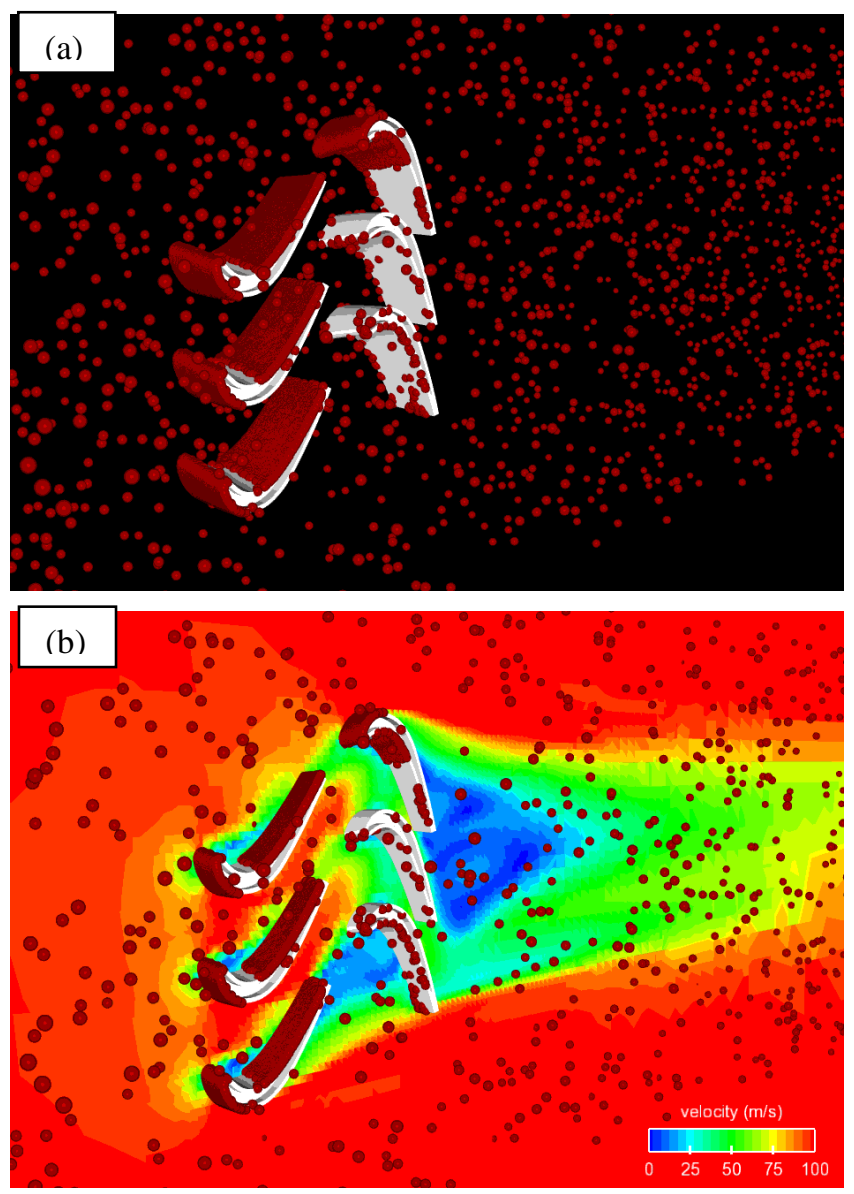

Figure 13. Particle trajectories for a fixed stator/rotor cascade (a) particulate flow and deposition dynamics, (b) streamwise velocity distributions in realistic turbulent environment.

Figure 13 shows the sand ingestion and particle transport around the three-dimension linear cascade geometry at the 
operating engine condition. Particles that have sufficient kinetic energy to deposit on the blade surface forming a film within the regions of viscous flow near the wall. The simulations show a higher rate of deposition on the stator row blades in comparison to the rotor blades. In general, the particle deposition is higher on the leading edge and the pressure surface as shown in Figure 13.

\section{EXPERIMENTAL EFFORTS}

ARL spray technologies were used to tailor dissimilar interfaces for densification of rigid particles during spray deposition processes (SPD, SPPS, HVAF, HVOF and APS) to generate the graded ceramic-metal and ceramic-composite material to be characterized [22-24]. Simultaneous deposition of ceramic and metallic materials can be achieved through the use of two or more powder feeders [12]. Post-processing of functionally-graded material (FGM) deposits via sintering and HIPing can be used to remove any porosity, increase the density and harden the outer ceramics for abrasion resistance. Coating constituent materials were selected based on evaluations with respect to thermal conductivity, phase stability, adhesion, strain tolerance, impact/erosion resistance, and CMAS-interaction. These coatings were deposited onto Inconel 718 one inch circular disks using Air Plasma Spray (APS), Solution Precursor Plasma Spray (SPPS), and Electron-Beam Physical Vapor Deposition (EB-PVD). The coatings were then evaluated using a high temperature button cell rig followed by a hot burner rig facility at ARL (shown in Figure 14). Typically, the coated samples were tested for three alternating thermal cycles of 3 minutes each (hot/cold) with high temperature maintained at $1300{ }^{\circ} \mathrm{C}$ (above sand melting point of $1140{ }^{\circ} \mathrm{C}$ ) and at $1 \mathrm{~g} / \mathrm{min}$ sand ingestion rate (AFRL 02 sand). AFRL 02 and AFRL 03 represent the state-of-the-art universal "average sand" developed by AFRL for conducting standardized sand ingestion tests for validation of gas turbine components' resistance against CMAS attack. AFRL 02 is generally comprised of smaller grains and used for bench-level and component-level testing. AFRL 03 exhibits larger grain distribution and is used for engine-level testing. Based on material morphology data after thermal cycling tests with sand particle ingestion, the performances of the coatings were determined and ranked. In addition to coating types, superfinishing of the coated surfaces were considered in the selection process.

From the candidate coatings, the top 11 promising coatings were selected and applied to 11 turbine nozzle doublets of a typical high pressure turbine nozzle ring. This turbine nozzle ring consisted of 12 nozzle doublets, with the remaining nozzle doublet used as the baseline (Reference nozzle doublet) with the coating as manufactured by the OEM. ARL-NASA and two coating vendors supplied the selected 11 different coatings/surface treatments for the eleven turbine nozzle doublets, as listed in Table-1. The turbine nozzle ring with the selected coatings applied is shown in Figure 15. The turbine nozzle ring with the eleven candidate coatings was then subjected to full engine test with mission relevant sand ingestion using the AFRL03 sand. Figure 16 shows borescope images of the nozzle vanes after the engine sand ingestion testing.

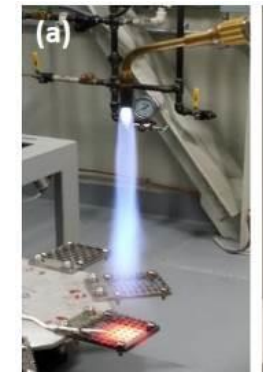

(a) Button-cell flame rig

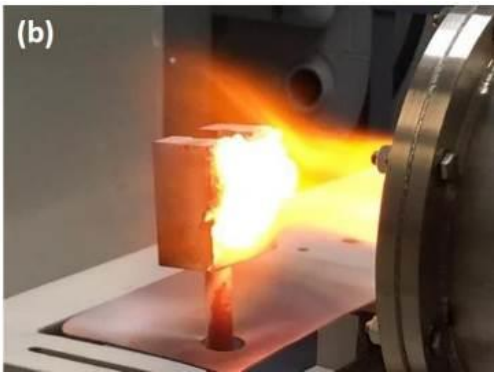

(b) Jet Burner rig
Figure 14. Button-cell flame testing rig \& hot particulate ingestion jet burner rig.

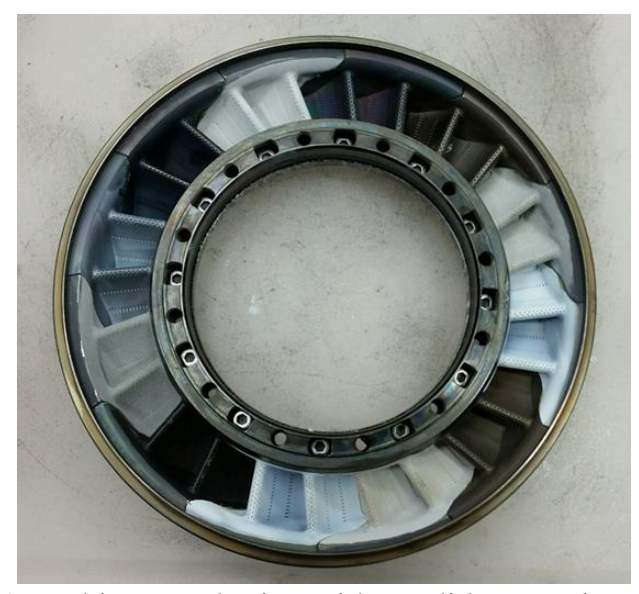

Figure 15. Turbine nozzle ring with candidate coatings

Table-1. Coating compositions evaluated

\begin{tabular}{|c|c|}
\hline Coating ID & Coating Composition \\
\hline $\mathbf{R}$ & Reference nozzle (as received from OEM) \\
\hline ARL-NASA-01 & NiCoCrAIY bondcoat (deposited with APS) with 8YSZ TBC (deposited by SPPS) \\
\hline ARL-NASA-02 & $\begin{array}{l}\text { NiCoCrAlY bondcoat (deposited with APS) with 7YSZ (deposited with APS), topped with Gd2O3 } \\
\text { (deposited with APS) }\end{array}$ \\
\hline ARL-NASA-03 & $\begin{array}{l}\text { NiCoCrAIY bondcoat (deposited with APS) with a blended TBC: } 70 \mathrm{vol} \% \text { 7YSZ + 30vol\%Gd2O3 } \\
\text { (deposited by APS); this is topped with a Gd2Zr2O7 ceramic (applied by APS) }\end{array}$ \\
\hline ARL-NASA-05 & $\begin{array}{l}\text { NiCoCrAlY bondcoat (deposited with APS) with blend of 70vol\%7YSZ + 30vol\%Gd2O3 (APS- } \\
\text { deposited) }\end{array}$ \\
\hline ARL-NASA-06 & $\begin{array}{l}\text { CODEP (TiC, Al) bondcoat with ZrO2-2.5mol\%Y2O3-1.0mol\%Gd2O3-1.0mol\%Yb2O3 (deposited } \\
\text { w/ EB-PVD) }\end{array}$ \\
\hline ARL-NASA-07 & $\begin{array}{l}\text { CODEP (TiC, Al) bondcoatwith HfO2-2.0mol\%Y2O3-2.0mol\%Gd2O3-16.0mol\% Yb2O3 (deposited } \\
\text { w/ EB-PVD) }\end{array}$ \\
\hline $\mathrm{s} 1$ & Supplied by Vendor-A \\
\hline s2 & Supplied by Vendor-A \\
\hline M1 & Supplied by Vendor-B \\
\hline M2 & Supplied by Vendor-B \\
\hline M3 & Supplied by Vendor-B \\
\hline
\end{tabular}



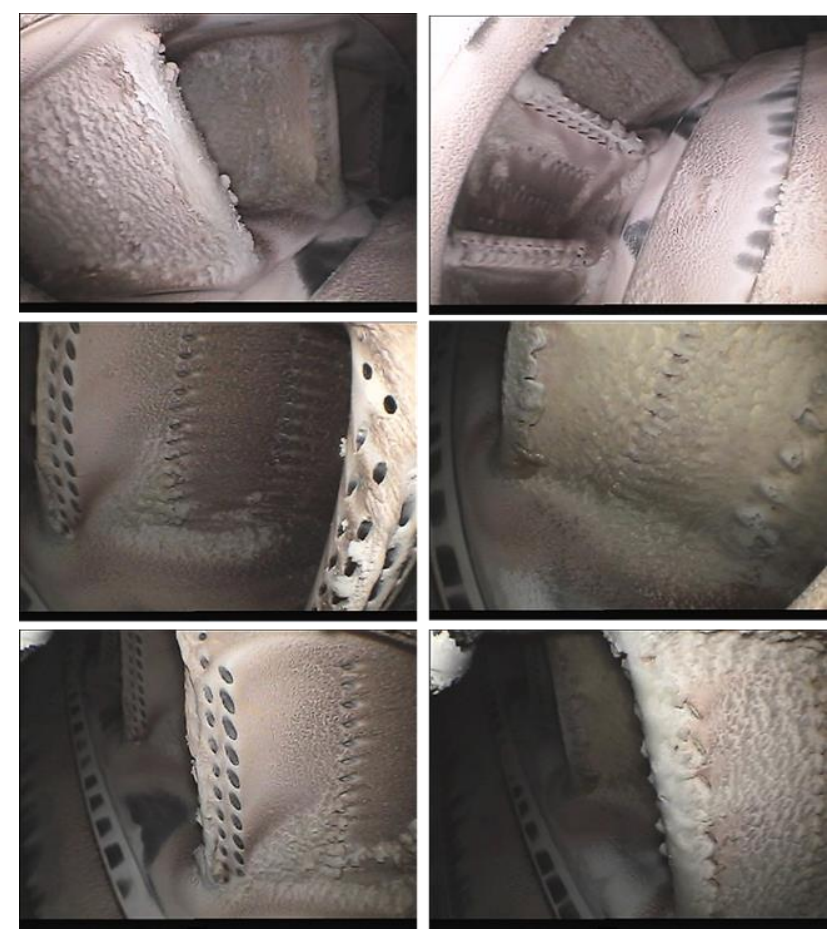

Figure 16. Borescope images of turbine nozzle vanes after sand ingestion test

Post-test examination of nozzle vanes included optical microscopy, confocal microscopy, scanning acoustic microscopy, CT-scan, and SEM to quantify the damage caused by CMAS on the various nozzle vanes with different types of coatings. In Figure 17, the post-test image of the reference nozzle vane doublet with the OEM supplied coating is shown. Figure 18 shows a SEM image of the CMAS deposited on the reference nozzle vane. This picture shows some micro sand particles entrained in the CMAS build-up on the vane surface. Figures 19 through 21 show the optical microscope images of two nozzle doublets with ARL-NASA-01 and ARL-NASA-05 coatings. From these photographs, the severity of cooling-hole blockage at the leading edge can be seen.

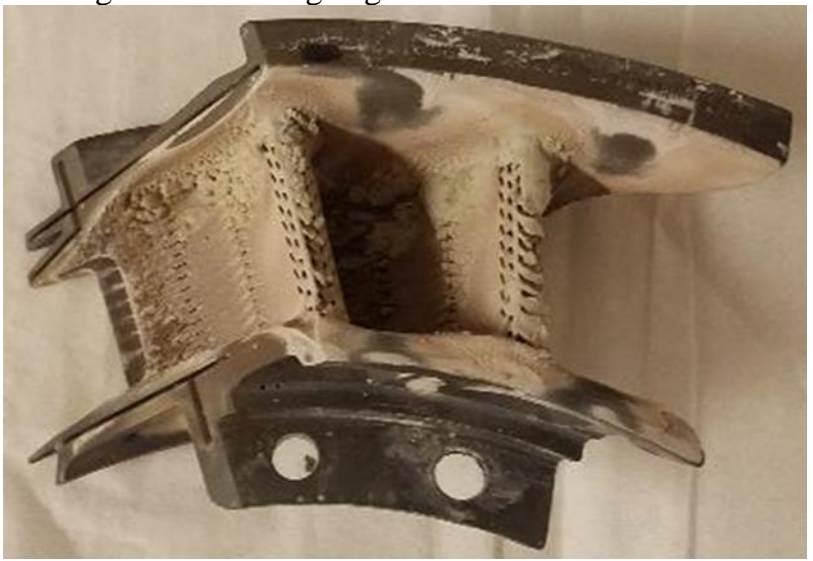

Figure 17. Reference nozzle with the OEM applied CoDEP coating

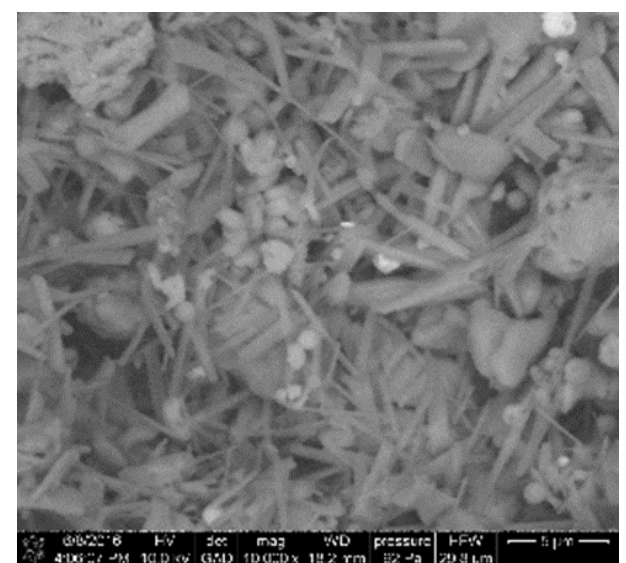

Figure 18. SEM image showing CMAS and particle accumulation

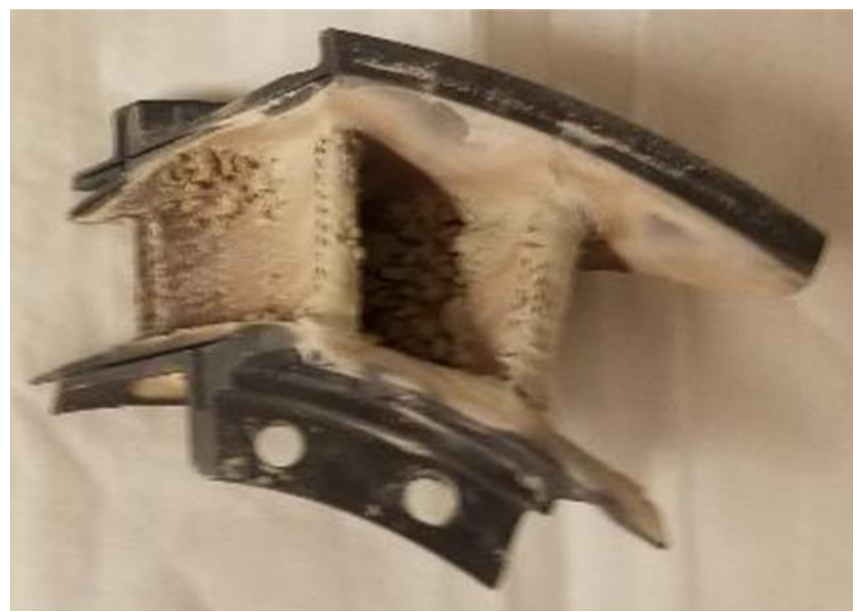

Figure 19. ARL-NASA-01 (8YSZ applied with SPPS) post-test picture

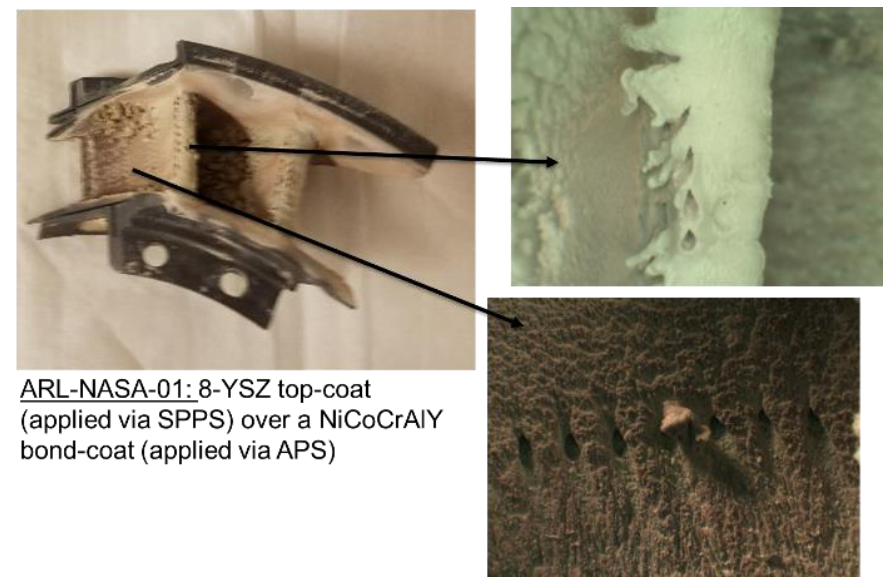

Figure 20. Optical microscopy analysis of coated nozzle with ARL-NASA-01 coating 


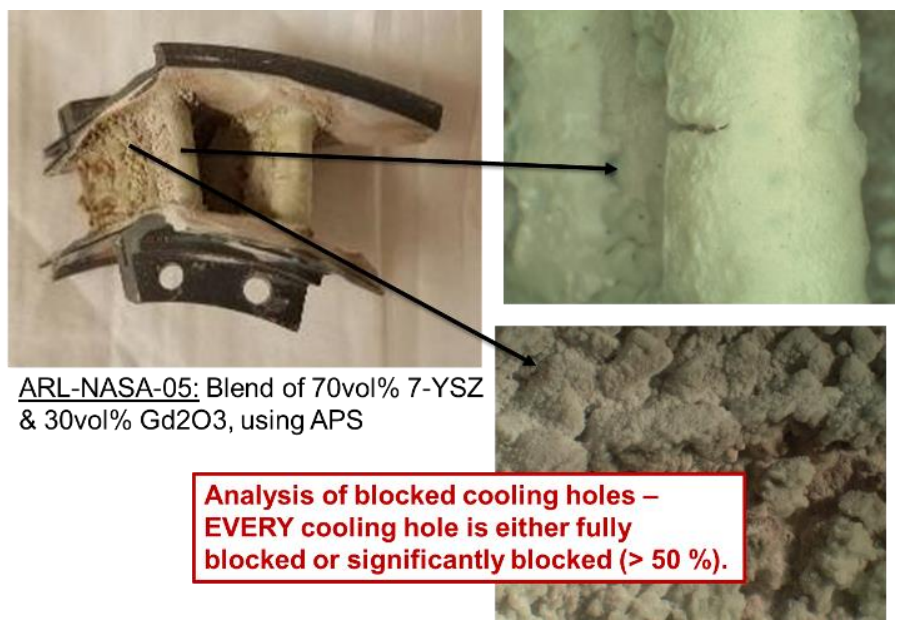

Figure 21. Optical microscopy analysis of ARL-NASA-05 coating

\section{Scanning Acoustic Microscopy Analysis}

Scanning acoustic microscopy (SAM) analysis is a technique that utilizes ultrasonic waves to non-destructively characterize sub-surface defects present within a material specimen or component. For the current study, the SAM was operated in reflection mode to generate a C-Scan (horizontal section), in which the elastic sound waves propagated onto the sample by the transducer are reflected back when there is a change in impedance, which is indicative of a change in acoustic properties due to defects or material property changes. The presence of CMAS was expected to generate an echo or reflection due to the differences in composition, as well as the relatively porous structure of the solidified CMAS.

Analysis of the post-test vanes was performed using a Sonoscan Gen6 SAM, operated with a $15 \mathrm{MHz}$ transducer and deionized water as the transducing medium. Subsurface imaging of the nozzle vanes was conducted by sequentially gating the reflected echo (ultrasound signal reflected back by sample) using a time interval of $1 \mu \mathrm{s}$. Sub-surface images of an air-cleaned nozzle vanes (little to no CMAS present) and the ARL-NASA-05 specimen are shown in Fig. 22. In the SAM analysis presented in Fig. 22(a) and (b), the sample was oriented so that the leading edges of the vanes were facing the transducer, that is, the orientation of the images is the same as that observed in the optical images in Fig. 17 and 21. Only one sub-surface slice is presented here for brevity. It can be seen that in addition to CMAS adhered on the outer walls, the subsurface air channel is also significantly clogged by sand. A similar analysis was conducted with the pressure side of the nozzle vanes oriented facing the transducer, as shown in Fig. 21 (c) and (d). Again, it can be seen that significant amounts of sand are seen throughout the image, corresponding to sand being present on both the surface and subsurface (i.e., cooling channels) of the airfoil. The presence of CMAS on the exterior and interior of nozzle vanes can have significant adverse effects on the aerodynamic and thermal performance of the component. The presence of sand within internal cooling channels indicates that the bleed air used was substantially contaminated by the sand laden flow.
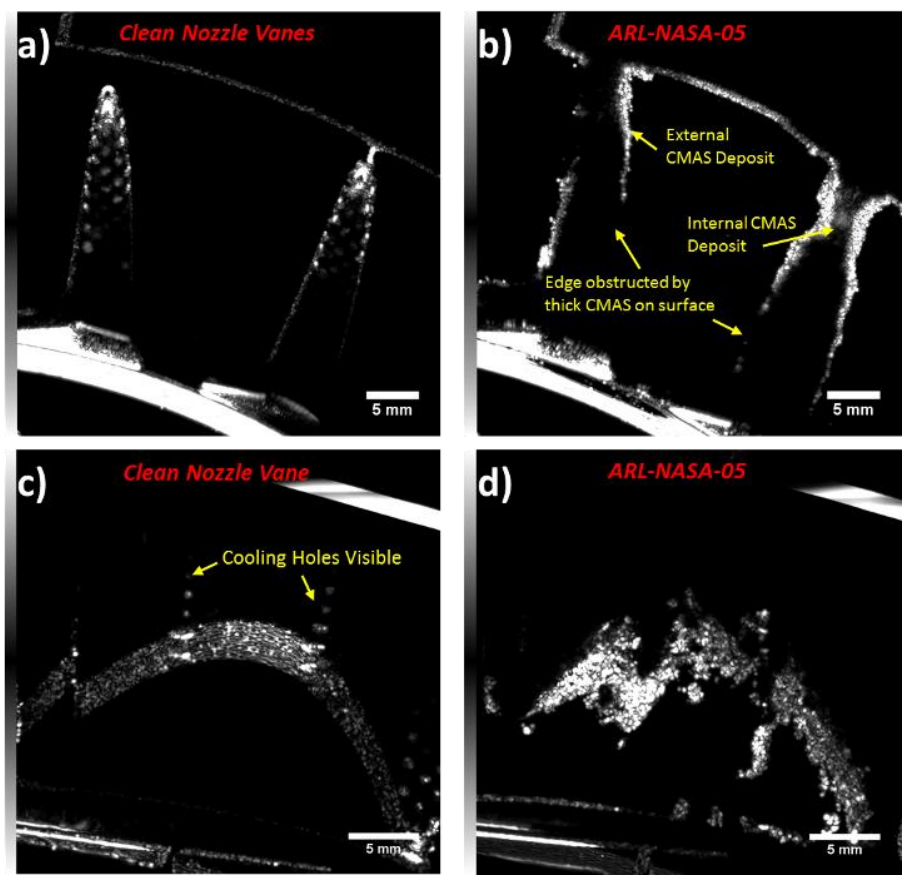

Figure 22. Scanning acoustic microscopy (SAM) analysis of nozzle vanes; a) and b) Sub-surface C-Scan of vane leading edge for air cleaned vanes (a) and ARL-NASA-05 (b); c) and d) C-Scan of vane pressure side for air cleaned vanes (c) and ARL-NASA-05 vane (d).

\section{CONCLUSION}

Sand ingestion is a serious problem for the hightemperature turbine blades of commercial and military aircraft and rotorcraft gas turbine engines. This paper reports the results and findings from the on-going modeling and experimental efforts that have been completed and currently underway on the development of multi-functional, high-temperature thermal barrier and sand-phobic coatings for future gas turbine application at the U.S. Army Research Laboratory. The following inferences are concluded from the current study:

- Quantitative understanding of the underlying physiochemistry is lacking, but canonical simulations are providing insight. Multiple particulate impacts cause increasing plastic strain damage.

- There is enough time for sand to fully melt while in the combustor. Molten sand particulate rebound velocities upon impact are nearly zero due to adhesion onto the TBC surface.

- Cooling-hole blockage has shown significant accumulation and adhesion of CMAS on multi-layered coatings with surface finish treatments.

- Scanning acoustic microscopy analysis has made it evident that the bleed air is substantially contaminated by fine sand laden flow resulting in the presence of sand in the internal 
micro-channels of nozzle vanes blocking the cooling flow. Coating processes and surface finish are being studied for reducing CMAS adherence and infiltration

Future research plans include:

- Continued morphology characterizations of the tested tailored thermal barrier coatings, especially CT-scan and cross-sectional SEM evaluations will be completed in the near future.

- Based on learnings from current efforts, novel coatings processes and surface finish treatments will be developed for:

- Layered TBC's

- Functionally gradient TBC's

- Integrated, functionally gradient CMC's for hot-section propulsion components (coatingless blades)

- Advanced modeling/analysis capability to develop future materials that effectively mitigate sand glazing and CMAS formation.

\section{ACKNOWLEDGMENTS}

The authors would like to thank and acknowledge the efforts and inputs from Mr. Robert Dowding, Dr. Jacob Temme, Mr. Richard Gerdom, Mr David Gondol, Mr. Mark Graybeal, and Mr. William Gamble at U.S. Army Research Laboratory. This research was sponsored by the U.S. Army Research Laboratory, U.S. Naval Air Systems Command, and the U.S. Army Aviation and Missile Research Development and Engineering Center. Part of this work was accomplished under a Cooperative Agreement with Oak Ridge Associated Universities (W911NF-12-2-0019)

\section{STANDARD DISCLAIMER}

The views and conclusions contained in this document are those of the authors and should not be interpreted as representing the official policies or positions, either expressed or implied, of the U.S. Army Research Laboratory, U.S. Naval Air Systems Command, the U.S. Army Aviation and Missile Research Development and Engineering Center or of the U.S. Government.

\section{REFERENCES}

[1] Smialek, J.L., Archer, F.A., and Garlick, R.G., "Turbine Airfoil Degradation in the Persian Gulf War," JOM, Vol. 46, 1994, pp. 39-41.

[2] Miller, R.A., "Current Status of Thermal Barrier Coatings An Overview," Surface \& Coatings Technology, Vol. 30, 1987, pp. 1-11.

[3]. Padture, N. P., Gell, M., and Jordan, E. H., "Thermal Barrier Coatings for Gas-Turbine Engine Applications," Science, Vol. 296, 2002, pp. 280-284.

[4] Borom, M.P., Johnson, C.A., and Peluso, L.A., "Role of Environment Deposits and Operating Surface Temperature in Spallation of Air Plasma Sprayed Thermal Barrier
Coatings," Surface \& Coatings Technology, Vol. 86, 1996, pp. 116-126.

[5] Levi, C.G., Hutchinson, J.W., Vidal-Setif, M.-H., and Johnson, C.A., "Environmental Degradation of Thermal Barrier Coatings by Molten Deposits," MRS Bulletin, Vol. 37, 2012, pp. 932-941.

[6] Kramer, S., Yang, J., and Levi, C.G., "Infiltration-Inhibiting Reaction of Gadolinium Zirconate Thermal Barrier Coatings with CMAS Melts," Journal of the American Ceramic Society, Vol. 91, 2008, pp. 576-583.

[7] Rai, A.K., Bhattacharya, R.S., Wolfe, D.E., and Eden, T.J., "CMAS-Resistant Thermal Barrier Coatings," International Journal of Applied Ceramic Technology, Vol. 7, 2010, pp. 662-674.

[8] Aygun, A., Vasiliev, A.L., Padture, N.P., and Ma, X., "Novel Thermal Barrier Coatings that are Resistant to High-Temperature Attack by Glassy Deposits," Acta Materialia, Vol. 55, 2007, pp. 6734-6745.

[9] Drexler, J.M., Shinoda, K., Ortiz, A.L., Li, D., Vasiliev, A.L., Gledhill, A.D., Sampath, S., and Padture, N.P., "Air Plasma-Sprayed Thermal Barrier Coatings that are Resistant to High-Temperature Attack by Glassy Deposits," Acta Materialia, Vol. 58, 2010, pp. 6835-6844.

[10] Hutchinson, J.W., Evans, A.G., "On the Delamination of Thermal Barrier Coatings in a Thermal Gradient”, Surface and Coatings Technology, Vol. 149, 2002, pp. 179-184.

[11] Suresh, S. and Mortensen, A., "Functionally Graded Metals and Metal-Ceramic Composites: Part 2 Thermomechanical Behaviour," International Materials Reviews, Vol. 42, 1997, pp. 85-116.

[12] Sampath, S., Herman, H. Shimoda, N., and Saito, T., "Thermal Spray Processing of FGMs," MRS Bulletin, Vol. 20, 1995, pp. 27-31.

[13] Murugan, M., Ghoshal, A., Walock, M.J., Barnett, B.D., Pepi, M.S., Hopkins, D., Gazonas, G., Kerner, K.A., "Blade Surface-Particle Interaction and Multifunctional Coatings for Gas Turbine Engine", 51st AIAA/SAE/ASEE Joint Propulsion Conference, Propulsion and Energy Forum, (AIAA 2015-4193).

[14] Schaedler, T., "Phase Evolution in the YO1.5-TiO2-ZrO2 System and Effects on Ionic Conductivity and Toughness," University of California-Santa Barbara, Santa Barbara, CA, 2006.

[15] LS-DYNA Keyword User's Manual, Version 971, Volume I, May 2007, Livermore Software Technology Corporation (LSTC), Livermore, CA.

[16] Phelps, A. and Pfedderer, L., "Development of a naturalistic test media for dust ingestion CMAS testing of gas turbine engine," in "Thermal Barrier Coatings IV", ECI Symposium Series, (2015).

http://dc.engconfintl.org/thermal_barrier_iv/29

[17] Tabakoff, W., 1991, "Measurements of Particles Rebound Characteristics on Materials used in Gas Turbines", Journal of Propulsion, Vol. 7, (5), 1991 pp. 805-813. 
[18] Hamed, A., "Effect of Particle Characteristics on Trajectories and Blade Impact Patterns", Journal of Fluids Engineering, Vol. 110, 1988, pp. 33-37.

[19] Murugan, D. M., Tabakoff, W., Hamed, A., "Computation of Particle Restitution Characteristics Using DYNA3D for Turbomachinery Application", 30th AIAA/ASME/SAE /ASEE Joint Propulsion Conference, Jun 27-29, 1994, Indianapolis, Indiana.

[20] Tabakoff, W., Murugan, D. M., Hamed, A., "Effect of Target Materials on the Particle Restitution Characteristics for Turbomachinery Application", 32nd Aerospace Sciences Meeting \& Exhibit, Jan 10-13, 1994, Reno, Nevada.

[21] Bravo, L., Wijeyakulasuriya, S., Pomraning, E., Senecal, P.K., Kweon, C.B., Large Eddy Simulation of High Reynolds Number Nonreacting and Reacting JP-8 Sprays in a Constant Pressure Flow Vessel With a Detailed Chemistry Approach, Journal of Energy Resources Technology, 138(3), 032207 (Mar 24, 2016), doi:
10.1115/1.4032901.

[22] Stöver, D., Pracht, G., Lehmann, H., Dietrich, M., Döring, J-E., Vaßen, R. "New Material Concepts for the Next Generation of Plasma-Sprayed Thermal Barrier Coatings", Journal of Thermal Spray Technology, Vol. 13, 2004, pp 76-83.

[23] Jordan, E.H., Xie, L., Ma, X., Gell, M., Padture, N.P., Cetegen, B., Ozturk, A., Roth, J., Xiao, T.D., Bryant, P.E.C. "Superior Thermal Barrier Coatings Using Solution Precursor Plasma Spray", Journal of Thermal Spray Technology, Vol 13, 2004, pp 57-65.

[24] Killinger, A., Gadow, R., Mauer, G., Guignard, A., Vaßen, R., Stöver, D. "Review of New Developments in Suspension and Solution Precursor Thermal Spray Processes" Journal of Thermal Spray Technology, Vol. 20, 2011, pp 677-695. 